\title{
Intelligent Management on the Home Consumers with Zero Energy Consumption
}

\author{
Kazem Khani ${ }^{* 1}$, Mohammad Iman Ghiasi ${ }^{2}$ \\ ${ }^{1}$ Department of Electrical Engineering, Islamic Azad University, Rodehen, Iran \\ ${ }^{2}$ Research Institute of Oil Company, Department of Electrical Engineering, Islamic Azad University, \\ Science \& Research Branch, Tehran, Iran \\ e-mail: Khani.Rasel@gmail.com
}

\begin{abstract}
The energy and environment crisis has forced modern humans to think about new and clean energy sources and in particular, renewable energy sources. With the development of home network, the residents have the opportunity to plan the home electricity usage with the goal of reducing the cost of electricity. In this regard, to improve the energy consumption efficiency in residential buildings, smart buildings with zero energy consumption were considered as a proper option. Zero-energy building is a building that has smart equipment whose integral of generated and consumed power within a year is zero. In this article, smart devices submit their power consumption with regard to the requested activity associated with the user's time setting for run times and end times of the work to the energy management unit and ultimately the time to start work will be determined. The problem's target function is reducing the energy cost for the consumer with taking into account the applicable limitations.
\end{abstract}

Keywords: Zero energy consumption home, energy supply planning, renewable energy, energy management.

\section{Introduction}

Recent research indicates that 20 to 30 percent of the energy consumed in the buildings can be reduced through optimized operation and management without a change in the structure of the building's energy supply system. In recent years, the increase in energy consumption and multiple restrictions on development of production resources triggered a comprehensive global study about energy consumption strategies on the demand side and at the same time to avoid damages to the process of development and growth of countries.

The energy management system of smart zero-energy consumption building controls and schedules energy consumption of smart loads. Despite the benefits to the customer by management of loads, it cannot be expected from small-sized households to act like an operator with experience in power systems or a skilled economist to mind their load planning and achieve the target function. Hence, there is a need for an approach that employs the least user intervention and by having sufficient information about the amount of power and duration of consuming of each smart load during consumption scheduling period, to manage the load according to the intended target function and the restrictions at hand [4].

In previous studies with the exception of article [3] of this document, so far it was assumed that electric devices can be connected and disconnected for an unlimited number of times during their activity periods which is not practical, also in other references, only the total energy consumption of each of electrical appliance and its range of performance regardless of changes, device's power consumption in its operational phases, and the consumption profiles were used; but in this study these weaknesses have been resolved [7].

The main objective of energy management system in this article is minimizing energy costs based on real-time electricity prices using the scheduling and planning of devices. In this project, a smart house is considered in which a part of its required energy needs is supplied locally by CHP generator, thermal, and electrical storage devices [5, 6].

Also, the given smart home can connect to upstream network to purchase network's power at peak hours and to sell excess power to the upstream network [15-16]. In the house, a number of household appliances such as dish-washer, washing-machine and electric oven are available In summary, innovations of this research include the following items: the use of probability distribution functions dependent on several factors such as seasonal and social 
coefficients for the time-scheduling of devices available in the house, introducing a new category of home appliances, taking into account the production of the amount of renewable energy such as solar panels [8-10].

\section{Research Method}

The article is divided into the following sections. In part 2, the problem is described in summary [2], [4]. In part 3, the mathematical model is explained and the restrictions, relevant assumptions and the target function are described. In section 4, the proposed model and simulation results will be introduced. Finally, section 5 is the conclusion [1], [5].

Table 1 shows the characteristics of the boiler used in this article.

\section{Table 1. View Boilers}

\begin{tabular}{cc}
\hline Rated power & $120 \mathrm{Kw}$ \\
Efficiency & $85 \%$ \\
Lifetime & $15 \mathrm{yrs}$ \\
& US\$ \\
fixed price & $(2700)$ \\
& US\$ \\
Replacement price & $(400)$ \\
Cost of operation and & US\$/yr \\
maintenance & $(900)$ \\
\hline
\end{tabular}

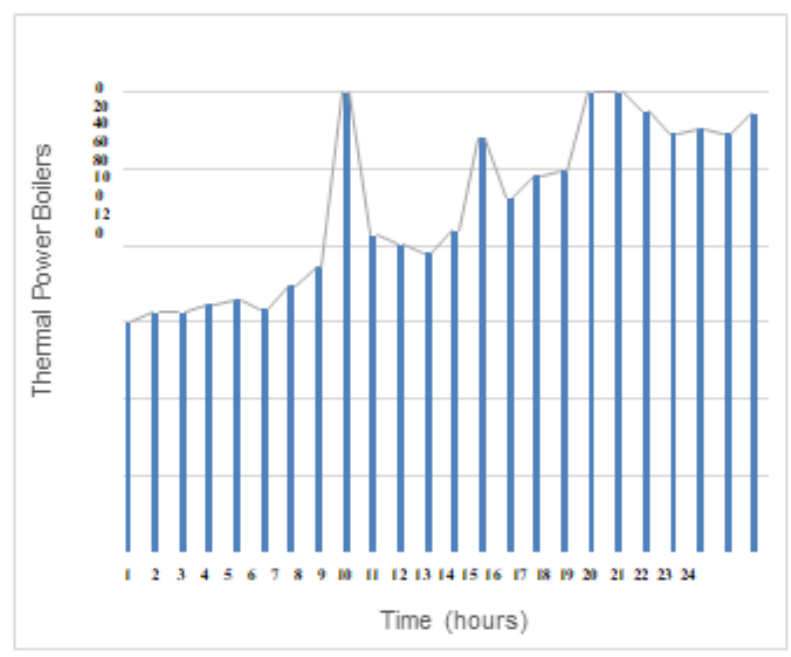

Figure 1. The thermal power boilers. Join consumption of electric car charging has been spent.

\section{Results and Analysis}

In a common domestic micro-network, there are three equipping categories: energy consumers, storage devices, and producers. The aim of minimizing energy cost during one day, will be defined as a linear combination integer planning and daily power consumption based on time-windows of equipment, between the earliest start-time of the work and latest end-time of the work [10], [13]. This simulation takes place in t time intervals and each one lasts one-hour and as a result, there are 24 intervals per diem [9]. 


\subsection{CHP generators}

The CHP generator consumes hydrogen and produces heat and electricity. Thermal and electrical outputs $\left(\mathrm{Pth}_{\mathrm{CHP}(\mathrm{t})}, \mathrm{P}_{\mathrm{CHP}(\mathrm{t})}\right)$ are defined as follows [2]:

$$
\begin{aligned}
& P t h_{C H P(t)}+P_{C H P(t)}=\eta_{C H P} \times M_{H} \\
& P t h_{C H P(t)}=\mu \times P_{C H P(t)} \\
& P_{C H P(t)} \leq C^{C H P}, \quad \forall t
\end{aligned}
$$

\subsection{Boiler}

The boiler output is a result of input natural gas energy and the efficiency of boiler tank [2]. The thermal output is considered with the use of energy per unit volume of gas, the amount of received gas at the time t, using the thermal efficiency in equations (5) and (6) and (7).

$$
\begin{aligned}
& P_{\text {thboiler }(t)} \leq C^{\text {boiler }}, \quad \forall t \\
& P_{\text {thboiler }(t)}=\eta_{\text {boiler }} \times g_{\text {gas }} \text { boiler }(t) \\
& \text { gas }_{C H P(t)}+g_{\text {as }} \\
& \text { boiler }(t)=g a s_{\text {total }}
\end{aligned}
$$

\subsection{Solar Panel}

The house is equipped with a solar panel mounted on the roof. In a solar system the output power should not exceed the specified upper limit which will be determined as follows [5].

$P_{\text {Photovoltaic }(t)} \leq P_{\text {Photovoltaic Limit }(t)}, \quad \forall t$

$P_{\text {Photovoltaic }(t)}^{\max }=\eta \times A \times I(t) \times[1-0.005 \times(\operatorname{Temp}(t)-25)]$

\subsection{Electric vehicles (PEV)}

The maximum power of electric vehicles per hour, minimum power of electric vehicles, balancing of their charge and storage of electric vehicles at cut off moment $t=t \mathrm{i}$ are set as follows $[10,11]$ :

$$
\begin{aligned}
& P_{\text {Storage } P E V(k, t)} \leq \text { Cap }_{\text {Storage PEV }(k)} \quad \forall k, t \\
& P_{\text {Storage } P E V(k, t=0)} \leq K_{P} \times \text { Cap }_{\text {Storage } P E V(k)} \quad \forall k, t \\
& P_{\text {Storage } P E V(k, t)}=P_{\text {Storage } P E V(k, t=1)}-P D_{\text {Storage } P E V(k, t)}+P C_{\text {Storage } P E V(k, t)} \quad \forall k, \mathrm{t} \\
& P_{\text {Storage } P E V\left(k, t=t_{i}\right)}=P_{t_{i}}\left(k, t=t_{i}\right) \quad \forall k
\end{aligned}
$$

\subsection{Energy Storage System}

Battery discharge rate should not exceed the specified limit which will be determined by the battery manufacturer. In order to avoid the extra charging and discharge rate that may cause damage to the battery, the following equations can be considered [6]:

$$
\begin{aligned}
& P_{\text {Storage Battery }(t)} \leq \text { Cap }_{\text {Storage Battery }} \quad \forall t \\
& P D_{\text {Storage battery }} \leq 0.5 \times \text { Cap }_{\text {Storage Battery }} \times X_{(t)} \\
& Y \in\{0,1\} \quad X \in\{0,1\} \quad \forall t \\
& P C_{\text {Storage battery }} \leq 0.5 \times \text { Cap }_{\text {Storage Battery }} \times Y_{(t)} \quad \forall t \quad Y \in\{0,1\} \\
& P_{\text {Storage Battery }(t)}=P_{\text {Storage Battery }(t-1)}-P D_{\text {Storage Battery }(t)}+P C_{\text {Storage Battery }(t)} \quad \forall t
\end{aligned}
$$




\subsection{Thermal Storage}

In addition, $\mathrm{t}-1$ energy is equal to the value stored at the time $\mathrm{t}$ heat stored in the thermal storage at the charge time minus the discharged energy [4]:

$$
\begin{aligned}
& P_{\text {Thermal }(t)} \leq \text { Cap }_{\text {Thermal }} \quad \forall \mathrm{t} \\
& P_{\text {Thermal }(t)}=P_{\text {Thermal }(t-1)}-P D_{\text {Thermal }(t)}+P C_{\text {Theraml }(t)} \quad \forall t \\
& P_{\text {Thermal }(t=0)}=P_{\text {Thermal }(t=24)}=P_{\text {Init Thermal }(t=0)}
\end{aligned}
$$

\subsection{Operational time-window of appliances}

Time to start any equipment cannot be earlier than the earliest start time of it and its operation must end before the latest time of completing its work. Any equipment in the house must be turned on once, and the relevant equations will be as follows [7]:

$\sum_{l=1}^{L}\left[\operatorname{LoadTD}(l) \times(1-X I T(l, t)]=\operatorname{Load}_{C}(t) \quad \forall t\right.$

This equation determines that how much the manageable loads at any time may affect the total load [12]. The time period of using the equipment in its operational time-window is determined by the following equation [10], [14]:

$\sum_{l=1}^{L}[(1-X I T(l, t)]=\operatorname{MainTD}(l) \quad \forall l$

The equations below guarantee the temporal continuity of manageable loads' performance:

$$
\begin{aligned}
& X I T(l, t)=1 \quad \forall t>t_{l} \quad \text { or } t<t_{e} \\
& U(l, t)-V(l . t)=X I T(l, t-1)-X I T(l, t) \quad \forall l, t \\
& U(l, t)+V(l, t) \leq 1 \quad \forall l, t \\
& \sum_{t=t_{e}}^{t_{l}} U(l, t)=1 \quad \forall l, t
\end{aligned}
$$

\subsection{The mathematical model home electricity use}

By setting the desired time-window as well as the time period of using the equipment, optimization will be able to determine the hours of using the equipment. For modelling the unmanageable equipment based on the likelihood of turning on the equipment by the probability function, the start of work will be determined [2]:

$P_{\text {Start }}\left(D, W, \delta, \sigma_{f}, h, d y\right)=P_{\text {season }}(D, W) P_{\text {Hour }}(D, h, d y) f(D, d y) P_{\text {Step }}(\delta) P_{\text {Social }}\left(\sigma_{f}\right)$

So, in above equation, $\mathrm{P}_{\text {season }}$ is the seasonal probability coefficient, $\mathrm{P}_{\text {Hour }}$ is the hourly probability coefficient that models the level of activity during the day, $\mathrm{P}_{\text {Step }}$ is the amount of step in the scale coefficient that scales the probability according to $\delta$, $\mathrm{P}_{\text {Social }}$ Social is the social random coefficient that models the social and climatic conditions affecting the people's behaviour, $\mathrm{f}$ is the average daily start of the work that models the average repeated use of an equipment, $\mathrm{D}$ is the device or group of devices, $\mathrm{h}$ is hour of the day، $\mathrm{W}$ is week of the year, $\sigma_{\mathrm{f}}$ is standard deviation of $P_{\text {Social }}$.

$P_{\text {Start }}$ is defined for any time period of $\delta$ and gets values between zero and one. When the device is turned off, the $P_{\text {Start }}$ probability checks the turning on. When this probability is more than the amount of the threshold probability, the equipment will be turned on. Then the soot of equipment's consumption is added to the load curve. When in accordance with the operational period of the equipment, the turn-on period ends, the equipment will be turned off. The probability coefficient of above equation has the following features:

$N_{\text {Step }} P_{\text {Step }}=1$
$N_{\text {Step }}=\frac{\delta}{60 \mathrm{~min}}$ 
$\frac{\sum_{W=1}^{52} P_{\text {Season }}(D, W)}{52}=1$

$\mathrm{N}_{\text {Step }}$ is the number of computational steps and $D_{n} \rho d y_{m}$ indicate the selected equipment during the day.

\subsection{The objective function}

The target function is shown in equation 1 consisting of 4 rows. The first line contains two sections. The first row contains two sections and the first part is related to the operational cost of the CHP's electrical section, the second part is the operational cost of the thermal part of CHP. The second row also consists of two parts and the first part relates to the operational cost of the boiler, the second part is the operational cost of photovoltaics. The third and fourth rows correspond to the operational cost of fuel cells, battery and PEV. The last row is the cost of exchange with the upstream network [3].

Minimize $f=$
$\operatorname{Min}\left[\sum_{t=1}^{T}\left(\begin{array}{l}P_{C H P(t)} \times C_{C H P(t)}+P t h_{C H P(t)} \times C t h_{C H P(t)}+P_{\text {thstorage }(t)} \times C_{\text {thstorage }(t)} \\ +P \text { th } h_{\text {boiler }(t)} \times C t h_{\text {boiler }(t)}+P_{\text {photovoltaic }(t)} \times C_{\text {photovoltaic }(t)} \\ +P D_{\text {storage battery }(t)} \times C D_{\text {Storage battery }(t)} \\ +\sum_{k=1}^{K}\left(P D_{\text {Storage } P E V(k, t)} \times C D_{\text {Storage } P E V(k, t)}\right) \\ P P_{\text {Grid }(t)} \times C P_{\text {Grid }(t)}-P S_{\text {Grid }(t)} \times C S_{\text {Grid }(t)} \\ \end{array}\right)\right]$

$f$ is the target function based on Dollars, $t$ is the time index based on hour (time horizon of planning in 24), one of the energy management incentives is reducing network peaks and thus avoiding the need for a network with more capacity. One way to achieve this goal is to increase network tariffs at peak period so as a result, subscribers will be persuaded to reduce consumption to cut electrical bills [2].

\subsection{Results of the implementation of the project 1}

This project is a combination of network scenario and the scenario of start to work of manageable loads at the earliest possible time that they may start to work. In this project, only the upstream network supplies the power and the heat is also only supplied via boiler. In this scenario, there is no other source of energy to supply the electrical and thermal loads. Also, any equipment is turned on at the earliest start time it may start to work and no action is taken in order to optimize the performance of equipment.

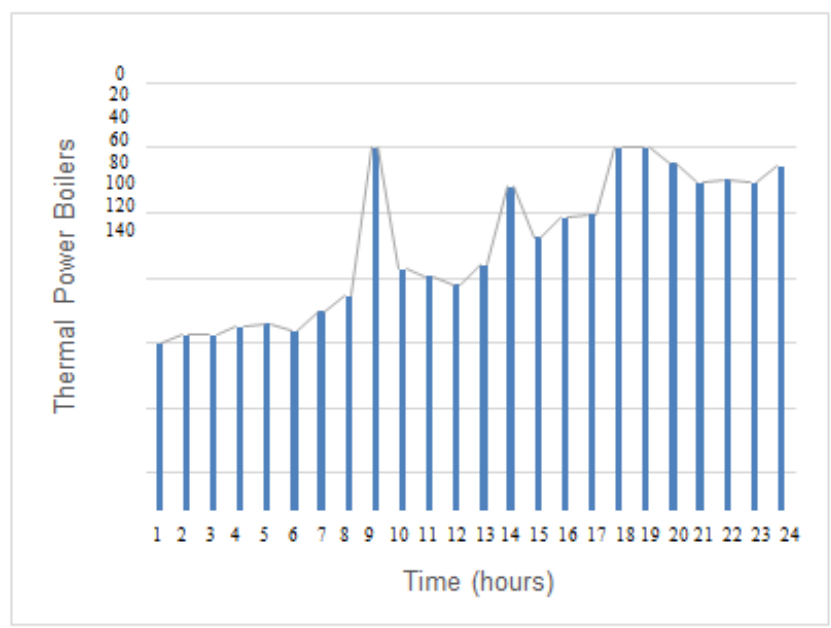

Figure 2. Thermal Power Boilers 
Figure 2 shows the thermal power boilers. Join consumption of electric car charging has been spent.

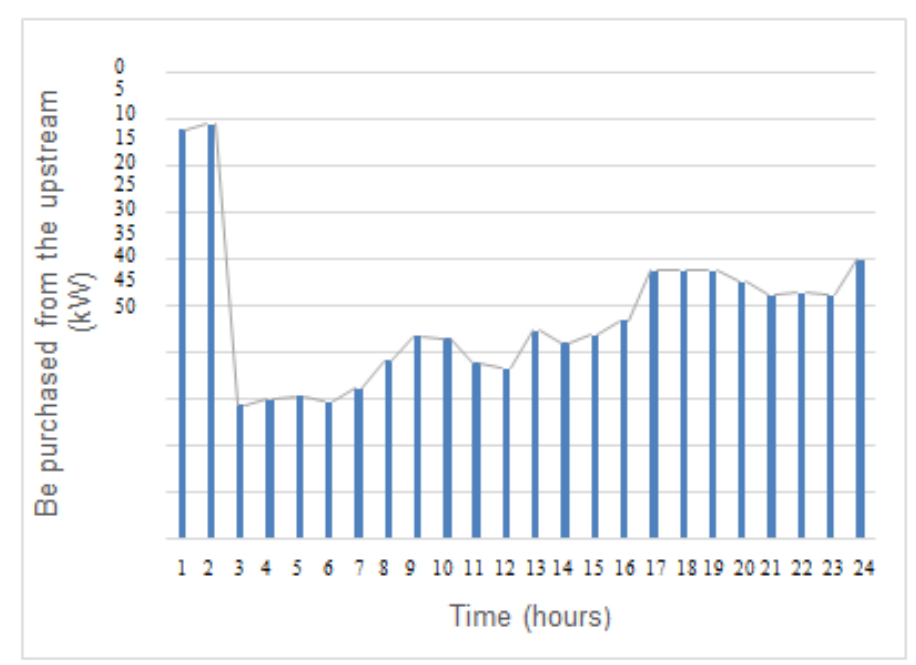

Figure 3. Be purchased from the upstream $(\mathrm{kW})$

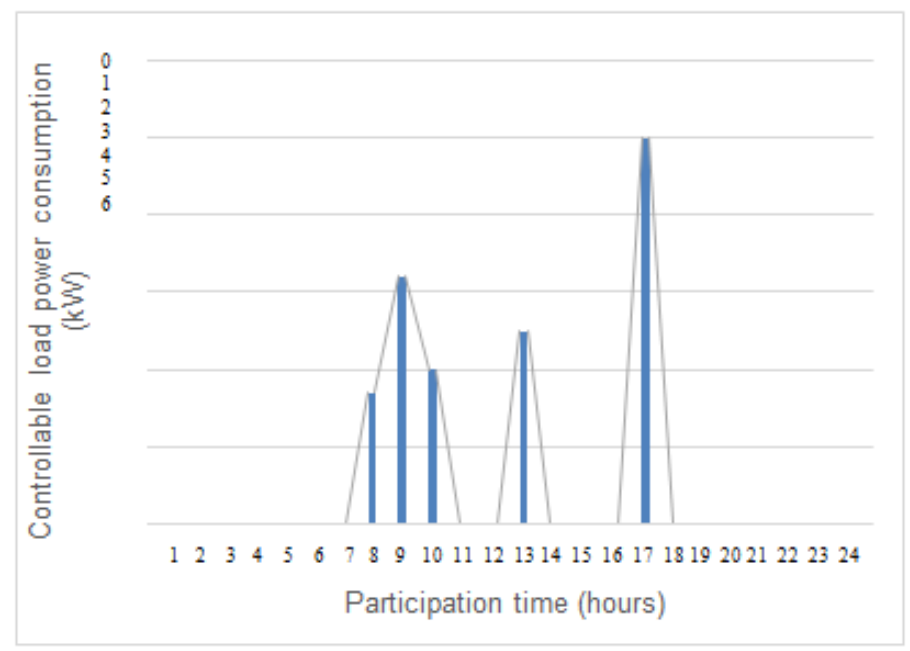

Figure 4. Controllable load power consumption (kW)

\section{Conclusion}

At network's peak load hours when usually the price of electricity is also high, the homes - relative to their dependence on the network- use their surplus production to help network operators to balance the supply and demand. This would reduce the operational problems at peak hours and reduces the production of fossil fuel power plants in these hours. Reducing the peak network load is also one of the results of smart energy management at home. This allows the houses to store electricity at low- consumption hours and use it at peak hours when the electricity price is high so the power demand on the network in those hours will drop. Increased competition at consumption side is another advantage of energy management. Because consumers have to use high-efficiency appliances with lower maintenance costs as their energy production sources to get the highest production with the lowest cost. Optimum use and control will have a dramatic effect on reducing the costs of the building. 


\section{References}

[1] Mohsenian-Rad, Leon-Garcia. Optimal Residential Load Control with Price Prediction In Real-Time Electricity Pricing Environments. IEEE Trans Smart Grid. 2010; (3)1: 33-120.

[2] Shirazi Elham, Jadid Shahram. Optimal residential appliance scheduling under dynamic pricing scheme via HEMDAS. Energy Build. 2015; 93: 9-40

[3] Motevasel Mehdi, Seifi Ali Reza. Expert energy management of a micro-grid considering wind energy uncertainty. Energy Convers Manage. 2014; 83: 58-72.

[4] Mayer Barbara, Killian Michaela, Kozek Martin. Management of hybrid energy supply systems in buildings using mixed-integer model predictive control. Energy Convers Manage. 2015; 98: 83-470.

[5] Katipamula S, Chassian DP, Hateley DD, Pratt RG, Hammerstrom DJ. Transacitive - controls, a market-based grid wise controls for building systems PNNL. Richard, WA:Pacific Northwest Natl. Lab. 2006; 1: 21-59.

[6] Alavi Seyed Arash, Ahmadian Ali, Aliakbar-Golkar Masoud. Optimal probabilistic energy management in a typical micro-grid based-on robust optimization and point estimate method. Energy Convers Manage. 2015; 314: 25-95.

[7] Iga A, Ishihara Y. Characteristics and embodiment of the practical use method of "Monthly Temperature Coefficient" of the photovoltaic generation system. IEE Jpn Trans Power Energy. 2006; 126(8): 75-767.

[8] Mossolly M, Ghali K, Ghaddar N . Optimal control strategy for a multi-zone airconditioning system using a genetic algorithm, Energy. 2009; 34(1): 58-66.

[9] Kriett Phillip Oliver A, Salani Matteo B. Optimal control of a residential microgrid. Energy. 2012; 42: 30-321.

[10] Zhang D, Shah N, Papageorgiou LG . Efficient energy consumption and operation management in a smartbuilding with microgrid Elsevier. Energy Convers Manage. 2009; 74: 22-209.

[11] Ortega-Vazquez Ma, Kirschen DS. Estimating the spinning reserve requirements in systems with significant wind power generation penetration. IEEE Trans Power Syst. 2009; 24: 24-114.

[12] Ozturk Y, Senthilkumar D, Kumar S, Lee G. An intelligent home energy management system to improve demand response. IEEE Trans Smart Grid. 2013; 4(2): 694-701.

[13] Villanueva D, Feijóo A. Wind power distributions: a review of their applications. Renew Sustain Energy Rev. 2010; 14: 5-1490.

[14] Youcef F, Mefti A, Adane A, Bouroubi MY. Statistical analysis of solar measurements in Algeria using beta distributions. Renew Energy. 2006; 26(1): 47-67.

[15] loakimidis Christos $S$ et al. Design, architecture and implementation of a residential energy box management tool in a SmartGrid. Energy. 2014; 175: 75-81.

[16] Soares N, Costa JJ. Gaspar AR, P Santosc D. Energy and Buildings. 2013; 59: 82-103. 